\title{
Protection of the Vascular Wall
}

\author{
Noble MIM* \\ Department of Medicine and Therapeutics, University of Aberdeen, Scotland
}

Submission: September 17, 2018; Published: October 09, 2018

*Corresponding author: Mark IM Noble, Department of Medicine and Therapeutics, University of Aberdeen, Scotland, Email: mimnoble@mac.com

Abstract

If one accepts that arterial glycocalyx dysfunction is the first step in the atherothrombotic process, screening of asymptomatic subjects could detect this change. Measurement of the arterial dilatation in response to increased arterial flow (FMD) is widely used in research and would seem to be a possible general non-invasive screening test in humans. Once there has been a break-down of this first line of protection, the second step in the atherothrombotic process might be effectively detected by measurement of blood platelet-platelet and platelet-leukocyte aggregates. While there is no clear treatment to counteract the first step other than exercise programmes, there is evidence to suggest that effective treatment of the second step could be achieved using 5HT2A antagonism.

Keywords: Vascular Wall; Arterial glycocalyx dysfunction; Atherothrombotic process

Abbreviations: EGL: Endothelial Glycocalyx; FMD: Flow Mediated Dilatation; Ach: Acetylcholine

\section{Introduction}

Primary prevention for vascular disease has, for some time now, been based on the administration of statins to people with high cholesterol levels or high-risk scores, e.g., NICE recommends wider use of statins for prevention of CVD [1]. However, this seems illogical in subjects free of vascular disease as these compounds have serious side effects. e.g., depression, myopathy and rhabdomyolysis. Should one be making normal people ill [2]? The policy is based on the theory that all vascular disease is caused by hyperlipidaemia, but other theories suggest more potent theories of causation, e.g., insulin resistance. There follows a commentary on the factors that are involved in disease of the arterial wall which might be more appropriate targets for preventative therapy.

\section{Endothelial glycocalyx dysfunction}

The smooth muscular structure of the vessel wall is separated from substances in the blood by two intimal layers - the endothelium and the Endothelial Glycocalyx (EGL). The theory that arterial glycocalyx dysfunction is the first step in the atherothrombotic process [3] has been found to be reasonable as summarised in 2018 [4]. For this to be compatible with the dogma that total cholesterol concentration is the cause of atherothrombosis, a search was made for the effect of this upon glycocalyx integrity. One such study suggests degradation of the endothelial surface layer by oxidised low density lipoprotein $(\mathrm{Ox}-$ LDL) as reflected in elevated capillary tube haematocrit $[5,6]$. A model of an arterial segment was developed to numerically simulate the flow and the transport of LDLs under normal and high pressure [7]; the transport parameters of the layers of the model were obtained from the hydrodynamic theory, the stochastic theory, and from the literature. The results showed that the increase in the thickness of the EGL could lead to a sharp drop in LDL accumulation in the intima. Aspects of these studies are (1) compatibility with the idea that LDL and not HDL may be involved in the genesis of atherothrombosis (2) patients should not be treated if the HDL is high, as only LDL is implicated in attacks on arterial protection. Further, there is no evidence that statins prevent glycocalyx dysfunction. Possibly rosuvastatin in heterozygous familial hypercholesterolemia [8] and sulodexide in patients with type 2 diabetes [9] may be effective in this regard. Administration of superoxide dismutase and catalase completely blocked the effect of Ox-LDL [5].

\section{Development of a test of endothelial function}

For primary prevention it would seem preferable to test endothial-glycocalyx function than assess risk by conventional scores based on total serum cholesterol. Obvious risks such as smoking diabetes and hypertension are obvious risks that should be dealt with by stopping smoking, controlling blood glucose soncetration and administrion of anti-hypertensive drugs. The damaging effect of high lumenal glucose concentration was discovered by Kelly et al [10] whose experiments were carried out in the anaesthetized pig in which pressure, blood flow and diameter of the left iliac artery were measured at two sites. Infusion of glucose attenuated the shear stress-dependent dilatation in both sections of the artery with preservation of the responses to acetylcholine. They concluded from these results that the hyperglycaemia-impaired dilatation is consistent with loss of mechano-transducing properties of the Endothelial Glycocalyx (EGL) by hyperglycaemia and postulated that this was a possible 
explanation for the increased incidence of vascular disease in diabetic and pre-diabetic patients.

The reason for regarding the glycocalyx as the important trigger for shear stress-dependent dilatation is that that response is attenuated when the gel structure of the glycocalyx is destoyed by hyaluronidase [11]. The attenuation of shear stressdependent dilatation by glucose is presumably due to increased glycosylation of the glycoprotein of the glycocalyx gel. The shear stress-dependent dilatation is commonly called Flow Mediated Dilatation (FMD), the mechanism of which has been discussed [12]. Impaired FMD is especially significant if the response to nitric oxide is normal.

\section{Application of FMD to humans}

The main method that has been adopted from this is to measure diameter changes of the brachial artery in reponse to increased flow, i.e., FMD, using ultrasound [13]. An alternative method of assessing endothlial function is to measure the response of flow to the endothelium-dependent vasodilator Acetylcholine (ACh), but this does not detect dysfuncion arising from the glycocalyx. Nevertheless, the use of these methods has produced a large literature on conditions in which endothelial dysfunction has been detected. It is no surprise that aging is one such. According to Seals et al. [16], several lifestyle and biological factors modulate vascular endothelial function with aging, including regular aerobic exercise, dietary factors (e.g. processed compared with non-processed foods), body weight/fatness, vitamin D status, menopause/oestrogen deficiency and a number of conventional and non-conventional risk factors for CVD. Given the number of older adults now and in the future, these authors call for more information is on effective strategies for the prevention and treatment of vascular endothelial aging. According to Celemajer et al. [17], loss of endothelium-dependent dilation in the systemic arteries occurs in the preclinical phase of vascular disease and is associated with interaction of the same risk factors known to predispose to atherosclerosis and its complications in later life. Once age, smoking diabetes and hypertension have been excluded, endothelial function testing would seem to be an encouraging way of assessing risk.

The principle idea for maintaining arterial integrity based on the evidence available is to encourage exercise programmes to promote FMD which is mediated by nitric oxide, thought to be an anti-atherome agent.

\section{The next step in the process of disease when glycocalyx protection has been overcome}

Degradation of the endothelial was found to cause adhesion to the endothelium of platelets and leukocytes [18]. This can be interpreted as the second step in the atherothrombotic process. How can one protect the arterial wall from this process? At this stage, there may be no symptoms, but one postulates that the adhered platelets and leucocytes form aggregates on the endothelium, it is possible that they break free and circulate; they can be detected without the need for microscopic analysis of blood smears [19]; samples can be fixed for later analysis [20,21] and could be the best marker of this stage of the process before angiography can detect full atheromatous lesions. Circulating platelet-leukocyte and platelet-platelet aggregates are found in inflammatory bowel disease by authors who claim this increases cardiovascular risk [22]. That risk can be detected by this method in the presence of normal angiography is shown in diabetic patients [23]. Less surprising is the detection of circulating aggregates in myeloproliferative disorders [24], transient cerebral ischemia [25] and full-blown coronary disease [26].

This evidence for a pre-thrombotic condition is compatible with the theory of thrombosis as a unitary hypothesis of cardiovascular risk [27] and in the absence of any evidence that statins inhibit the formation of aggregates, one might think it logical to treat these patients with anti-thrombotic drugs. However, we are discussing a sort of borderline state between asymptomatic people who may be developing an unprotected state of the vessel wall, so that to expose such people to the considerable risk of a worse outcome due to bleeding complications is unwise.

\section{Possible treatment of patient with platelet aggregates indicating the likelihood of platelet-leucocyte adher- ence to the endothelium}

This possibility comes from the work of Menys [28], who showed that aggregate growth in vitro is inhibited by a serotonin 5HT2A receptor antagonist. The reason for this is that aggregate and platelet rich thrombus growth occurs when activated platelets release serotonin from the dense granules, such serotonin activates more platelets via the platelet 5 HT2A receptor [29]. The antagonist used by Menys was also shown to inhibit and disperse growing thrombi in the coronary artery [30]. The great advantage of this approach is that the drug used by McAuliffe et al [30] has no effect on bleeding from wounds [31] which do not contain serotonin. If the sceening and institution of 5HT2A antagonism could be organised, one might be able to prevent progression to the development of atherothrombotic lesions that would necessitate secondary prevention with statins and dual anti-platelet treatment.

\section{Conclusion}

Protection of the arterial wall from initiation and progression of the first manifestations of vascular disease is theoretically possible, but fraught with practical difficulties. It would be a programme that would make primary prevention with statins unnecessary.

*ICI170809, now patented by Thromboserin Ltd with the trade name Arteclere.

\section{References}

1. NICE (National Institute for Health and Care Excellence).

2. Gérvas J (2014) Adverse effects of statins. BMJ 348: g3306.

3. Noble MI, Drake-Holland AJ, Vink H (2008) Hypothesis: arterial glycocalyx dysfunction is the first step in the atherothrombotic process. QJM 101(7): 513-518. 


\section{Journal of Cardiology \& Cardiovascular Therapy}

4. Drake-Holland AJ (2018) Development of the damaged glycocalyx hypothesis - A review. Open access text.

5. Vink H, Constantinescu AA, Spaan JA (2000) Oxidized lipoproteins degrade the endothelial surface layer: implications for plateletendothelial cell adhesion. Circulation 101(13): 1500-1502.

6. Constantinescu AA, Vink H, Spaan JA (2001) Elevated capillary tube hematocrit reflects degradation of endothelial cell glycocalyx by oxidized LDL. Am J Physiol Heart Circ Physiol 280: H1051-1057.

7. Liu X, Fan Y, Deng X (2011) Effect of the endothelial glycocalyx layer on arterial LDL transport under normal and high pressure. J Theor Biol 283(1): 71-81.

8. Meuwese MC, Mooij HL, Nieuwdorp M, van Lith B, Marck BR, et al. (2009) Partial recovery of the endothelial glycocalyx upon rosuvastatin therapy in patients with heterozygous familial hypercholesterolemia. J Lipid Res 50(1): 148-153.

9. Broekhuizen LN, Lemkes BA, Mooij HL, Meuwese MC, Verberne H, et al. (2010) Effect of sulodexide on endothelial glycocalyx and vascular permeability in patients with type 2 diabetes mellitus. Diabetologia 53(12): 2646-2655

10. Kelly R, Ruane- O'Hora T, Noble MIM, Drake-Holland AJ, Snow HM (2006) Differential inhibition by hyperglycaemia of shear stressbut not acetylchomine- mediated dilatation in the iliac artery of the anaesthetized pig. J Physiol 573(Pt 1): 133-145.

11. Mochizuki S, Vink H, Hiramatsu O, Kajita T, Shigeto F, et al. (2003) Role of hyaluronic acid glycosaminoglycans in shear-induced endotheliumderived nitric oxide release. Am J Physiol Heart Circ Physiol 285(2): H722-H726.

12. Markos, F, Ruane O'Hora, T, Noble MI (2013) What is the mechanism of flow mediated arterial dilatation? Clin Exp Pharmacol Physiol 40(8): 489-494.

13. Anderson EA, Mark AL (1989) Flow-mediated and reflex changes in large peripheral artery tone in humans. Circulation 79(1): 93-100.

14. Agewall S, Doughty RN, Bagg W, Whalley GA, Braatvedt G, et al. (2001) Comparison of ultrasound assessment of flow-mediated dilatation in the radial and brachial artery with upper and forearm cuff positions. Clin Physiol 21(1): 9-14.

15. Al-Qaisi M, Kharbanda RK, Mittal TK, Donald AE (2008) Measurement of endothelial function and its clinical utility for cardiovascular risk. Vasc Health Risk Manag 4(3): 647-652.

16. Seals DR, Jablonski, Donato AJ (2011) Aging and vascular endothelial function in humans. Clin Sci (Lond) 120(9): 357-375.

17. Celermajer DS, Sorensen KE, Bull C, Robinson J, Deanfield JE (1994) Endothelium-dependent dilation in the systemic arteries of asymptomatic subjects relates to coronary risk factors and their interaction. J Am Coll Cardiol 24(6): 1468-1474.

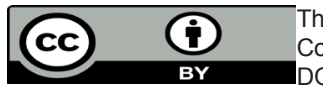

18. Constantinescu AA, Vink H, Spaan JA (2003) Endothelial cell glycocalyx modulates immobilization of leukocytes at the endothelial surface. Arterioscler Thromb Vasc Biol 23(9): 1541-1547.

19. Li N, Goodall AH, Hjemdahl P (1999) Efficient flow cytometric assay for platelet-leukocyte aggregates in whole blood using fluorescence signal triggering. Cytometry 35(2): 154-161.

20. AGGFix. fixation of platelet aggregates and other blood cell conjugates prior to immunofluorescence staining and flow cytometric analysis. Platelet Solutions, University of Nottingham. PSR-002A/2B.

21. Algahtani $M$ et al (2015) A new approach to measuring platelet aggregation and platelet-leucocyte conjugate formation in a small volume of fixed whole blood. Poster presentation P0410-TUE ISTH.

22. Tekeliogu Y, Uzan H (2013) Circulating platelet-leukocyte aggregates in patients with inflammatory bowel disease. J Chin Med Assoc 76(4): 182-185.

23. Elalamy I, Chakroun T, Gerotziafas GT, Petropoulou A, Robert F, et al. (2008) Circulating platelet-leukocyte aggregates: A marker of microvascular injury in diabetic patients. Thromb Res 121(6): 843848.

24. Jensen MK, de Nully Brown P, Lund BV, Nielsen OJ, Hassel balch HC (2001) Increased circulating platelet-leukocyte aggregates in myeloproliferative disorders is correlated to previous thrombosis, platelet activation and platelet count. Eur J Haematol 66(3): 143-151.

25. Wu, KK, Hoak JC (1975) Increased platelet aggregates in patients with transient ischemic attacks. Stroke 6(5): 521-524.

26. Furman MI, Benoit SE, Barnard MR, Valeri CR, Borbone ML (1998) Increased Platelet Reactivity and Circulating Monocyte-Platelet Aggregates in Patients with Stable Coronary Artery Disease. J Am Coll Cardiol 31(2): 352-358.

27. Noble MIM (1995) Thrombosis as a unitary hypothesis of cardiovascular risk. Journal of Cardiovascular Risk 2: 177-179.

28. Menys VC (1993) Collagen induced human platelet aggregation: serotonin receptor antagonism retards aggregate growth in vitro. Cardiovascular Research 27(11): 1916-1919.

29. Holmsen H (1977) Prostaglandin Endoperoxide - Thromboxane Synthesis and Dense Granule Secretion as Positive Feedback Loops in the Propagation of Platelet Responses during "The Basic Platelet Reaction". Thromb Haemost 38(4): 1030-1041.

30. McAuliffe SJG, Snow HM, Cox B, Smith CTT, Noble MIM (1993) Interaction between the effect of 5-hydroxytryptamine and adrenaline on the growth of platelet thrombi in the coronary artery of the anaesthetised dog. British Journal of Pharmacology 109(2): 405-410.

31. Noble MIM, Ford I, Cameron G, Drake-Holland AJ (2017) The Novel Anti-Thrombotic Drug with No-Bleeding Excess. J Cardiol \& Cardiovasc Ther 6(2): 555684.

\section{Your next submission with Juniper Publishers will reach you the below assets}

- Quality Editorial service

- Swift Peer Review

- Reprints availability

- E-prints Service

- Manuscript Podcast for convenient understanding

- Global attainment for your research

- Manuscript accessibility in different formats

( Pdf, E-pub, Full Text, Audio)

- Unceasing customer service

Track the below URL for one-step submission

https://juniperpublishers.com/online-submission.php 